\title{
A Knowledge-Based Digital Dashboard for Higher Learning Institutions
}

\author{
${ }^{1}$ Wan Maseri Binti Wan Mohd, ${ }^{2}$ Abdullah Embong, and ${ }^{3}$ Jasni Mohd Zain \\ Faculty of Computer System \& Software Engineering \\ University Malaysia Pahang \\ 1maseri@ump.edu.my, aembong@ump.edu.my, asni@ump.edu.my
}

\begin{abstract}
We propose a novel approach of knowledge discovery method by adopting dashboard concept and incorporating elements of data clustering, visualization and knowledge codification. The dashboard was designed to help the higher institution to explore the insight of student performance by analyzing significant patterns and tacit knowledge of the experts in order to improve decision making process. The system has been developed using system development life cycle (SDLC) methodology and coded in web-based and open source environment. The dashboard architecture and software are presented in this paper.
\end{abstract}

Keywords: Knowledge Management, Digita Dashboard, Data Mining, Knowledge Discovery, Data Visualization, Knowledge Visualization.

\section{Introduction}

Major application of knowledge discovery identified for higher education institutions is student performance [1]. It is critical for the higher educationist to identify and analyze the relationships among different entities such as students, subjects, lecturers, environment and organizations to ensure the effectiveness of their important processes. Presently, Higher Education Institutions are just utilizing normal report with minimum knowledge exploration to analyze information regarding the performance of the institution such as student performance.

The objective of this project is to design and develop a University Dashboard system to improve the knowledge exploration by combining various techniques; MaxD $\mathrm{K}$-means data clustering technique, graph-based visualization technique, knowledge management elements and dashboard concept. With the new approach of knowledge exploration, it shall helps the Board of Examiner or Senate Members to further explore the findings from the processing of information through the combination of clustering process and visualizing technique in identifying problems and actions to be taken in order to improve student performance.

\section{A Novel Digital Dashboard for Higher Education Institution}

\subsection{Novelty of the Dashboard}

The new digital dashboard for higher education is able to increase the utilization and effectiveness of the generated knowledge to facilitate the decision making process. It 
incorporates Knowledge Codification Technique, Data Clustering (Data Mining), Forecasting Technique, Graph-based Visualization technique and Digital Dashboard concept. The new university dashboard has various advantages and uniqueness compared to the current dashboard as shown in Table 1.

Table 1. Comparison of Features and Uniqueness between new University Dashboard and current Dashboard

\begin{tabular}{|c|c|c|}
\hline No & New University Dashboard & Current Dashboard \\
\hline 1 & $\begin{array}{l}\text { Illustrate the Overall Summary of Student } \\
\text { Performance at a glance using Dashboard Concept } \\
\text { and incorporating Key Performance Indicator. }\end{array}$ & $\begin{array}{l}\text { The current dashboard is just a normal reporting } \\
\text { without incorporating the Key Performance } \\
\text { Indicator and display details without summary for } \\
\text { the University. }\end{array}$ \\
\hline 2 & $\begin{array}{l}\text { Incorporating Data Mining engine to cluster the } \\
\text { Student's Result for knowledge exploration }\end{array}$ & $\begin{array}{l}\text { The current system does not incorporate Data } \\
\text { Mining process. The results are only go through } \\
\text { normal information retrieval with predefine } \\
\text { requirements }\end{array}$ \\
\hline 3 & $\begin{array}{l}\text { Incorporating Forecasting engine to forecast the } \\
\text { Future Student Performance }\end{array}$ & $\begin{array}{l}\text { The current system does not incorporate forecasting } \\
\text { engine. It only displays the current status and } \\
\text { history. }\end{array}$ \\
\hline 4 & $\begin{array}{l}\text { Incorporating Opinions from Education Experts on } \\
\text { the student performance and suggestion for } \\
\text { improvement as part of knowledge management } \\
\text { mechanism. }\end{array}$ & $\begin{array}{l}\text { The current report does not include expert opinion. } \\
\text { Opinions are recorded as part of meeting minutes } \\
\text { without proper documentation - no knowledge } \\
\text { management mechanism. }\end{array}$ \\
\hline 5 & $\begin{array}{l}\text { Incorporating Related Publications such as article, } \\
\text { conference proceeding, paperwork and technical } \\
\text { report which relates to the student performance. }\end{array}$ & $\begin{array}{l}\text { No sufficient research being done to improve } \\
\text { student performance. The findings are not attached } \\
\text { to the academic system for review or to help in } \\
\text { decision making. }\end{array}$ \\
\hline 6 & $\begin{array}{l}\text { Incorporating Drill-down Features to zoom into } \\
\text { Cluster's Behavior and Analysis by Faculty, year } \\
\text { and race }\end{array}$ & $\begin{array}{l}\text { Drill down only for faculty, year, race etc, but not to } \\
\text { detail student's behavior. Student behavior is not } \\
\text { captured in any university application. }\end{array}$ \\
\hline 7 & $\begin{array}{l}\text { Incorporating Knowledge Management Elements to } \\
\text { process the Explicit Knowledge such as Data } \\
\text { Clustering of Student's Result, Detail Student } \\
\text { Behavior and Analysis of Results. }\end{array}$ & $\begin{array}{l}\text { Very limited knowledge management for explicit } \\
\text { knowledge. The current system just display result } \\
\text { without exploring the insight of the information. }\end{array}$ \\
\hline 8 & $\begin{array}{l}\text { Incorporating Knowledge Management Elements to } \\
\text { process the Tacit Knowledge such as Expert } \\
\text { Opinion and Skill and Experience through } \\
\text { publications such as knowledge bank in the terms of } \\
\text { Technical Report, Article, Journal, Paperwork and } \\
\text { etc. }\end{array}$ & $\begin{array}{l}\text { The current systems display only the result of } \\
\text { explicit knowledge without tacit knowledge. }\end{array}$ \\
\hline
\end{tabular}

\subsection{Applicability}

Student Performance is one of the benchmark scale which reflect the Institution performance level. To really explore and improve the student performance, knowledge exploration is deemed crucial, thus the need for new KMS is highly demanded. Presently, Higher Education Institutions are just utilizing normal student report with minimum knowledge exploration to analyze student performance. With the new KMS, it shall helps the Board of Examiner or Senate Members to further explore the findings from the processing of information through the combination of knowledge processing and visualizing technique to identify problems and actions to be taken in order to improve student performance. 


\subsection{System Architecture}

Fig. 1 shows the system architecture of the dashboard where the process starts from the data capturing from University Database, followed by data clustering process, visualizing process, forecasting process and finally viewing the final results through the dashboard view. Parameter-less K-Means clustering engine was used for data clustering process [2], Multi-layers graph-based technique was used to visualize the generated clusters [3] and fuzzy pattern matching algorithm was used to forecast future performance. At the same time, input from Key Performance Indicator (KPI) System will generate the dashboard for the targeted KPI as a comparison to the current status. For the above processing, interaction with the domain experts shall improve the intelligence of the system.

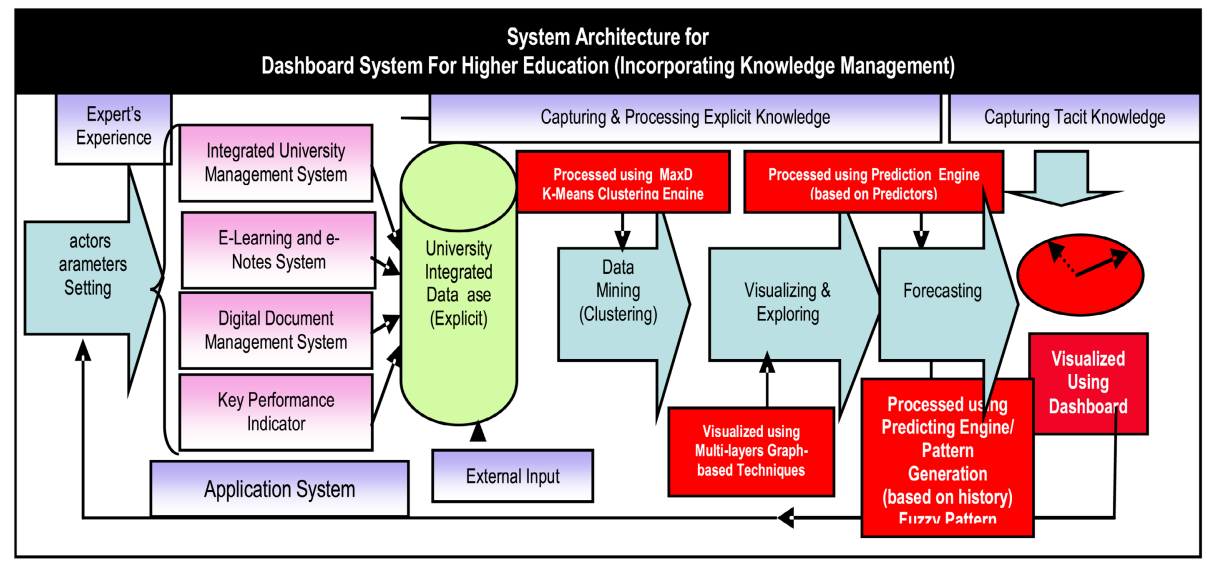

Fig. 1. System Architecture of University Dashboard

\subsection{Snapshots of a Knowledge-Based Digital Dashboard}

Fig.2 shows the Max-D K-means Clustering engine [2] used to cluster the student performance data and Fig. 3 shows the forecasting engine which forecast the future academic performance of using Fuzzy Pattern Matching Algorithm. The output of these processing is visualized through the digital dashboard [3] as shown in Fig.3(a) and Fig.3(b) which illustrate the use of dashboard concept with various knowledge exploration techniques; clustering, visualization and knowledge codification [4]. At a glance, the management of the institution can have a feel of their institutions in terms of student performance. In first segment of the dashboard, it shows the current status of the overall performance, followed by the forecast performance and pervious performance. As such, it allows the management to visualize and appreciate the actual performance compared to the previous and future performance. Furthermore, the dashboard shows the student clusters generated from clustering process of the student performance database in the form of graph. Each cluster can be drilled down using multi-layers graph-based technique to visualize the behavior of the students. The clusters allow the management to visualize the group of student in a particular category 
and further actions can be taken immediately. The dashboard is also comprises of expert opinion which is part of tacit knowledge and related publications for the subject matter as part of explicit knowledge. This segment illustrates the use of knowledge codification technique in the dashboard. Finally, the drill-down features of the dashboard is illustrated through the detail graphs whereby it shows the breakdown of the student performance by various dimensions such as faculty, gender, race etc. The detail information of each graph shall be displayed in the next layer of the dashboard, which becomes the sub-dashboard for the purpose of different group of users.

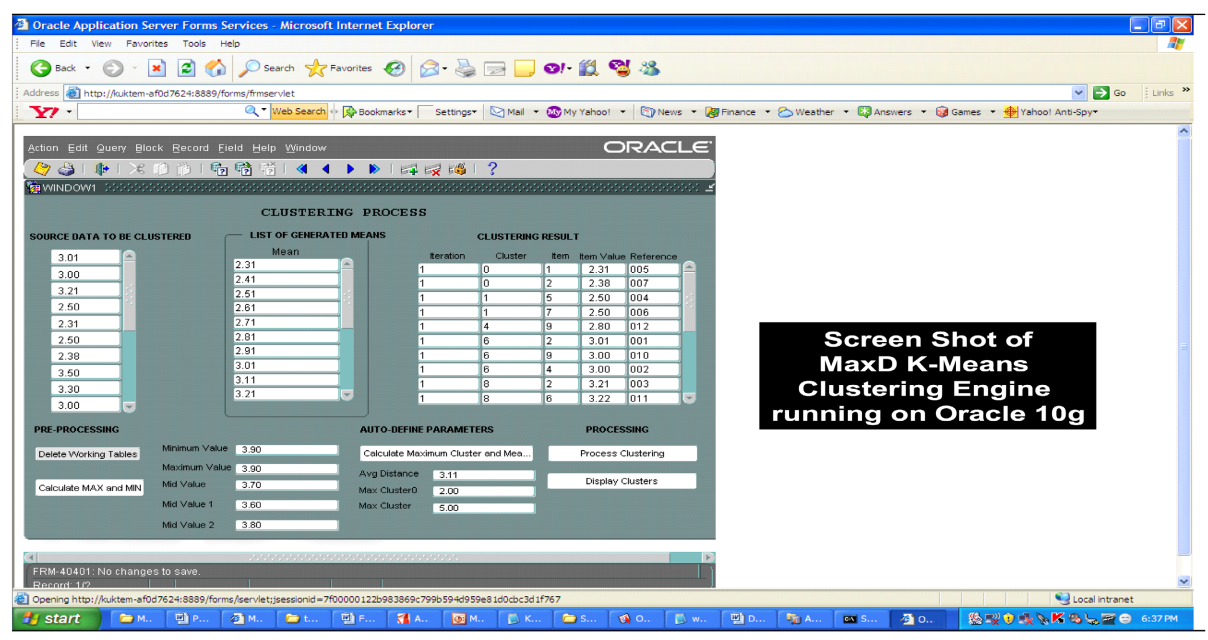

Fig. 2. Max-D Clustering Engine

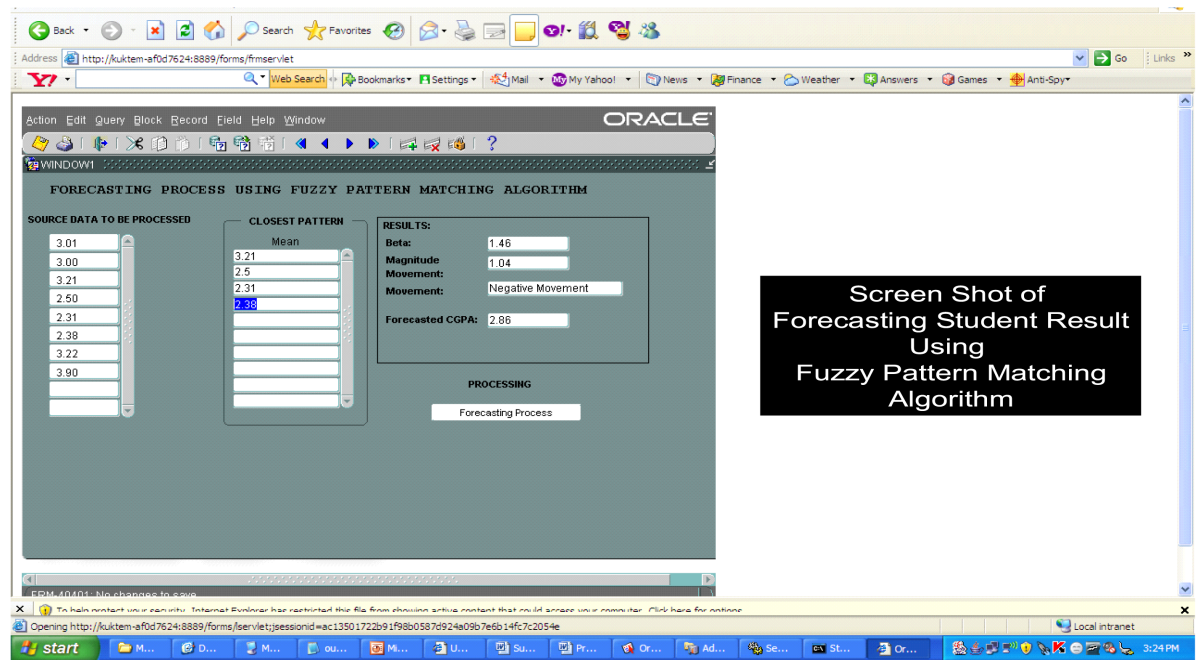

Fig. 3. Fuzzy Pattern Forecasting Engine 


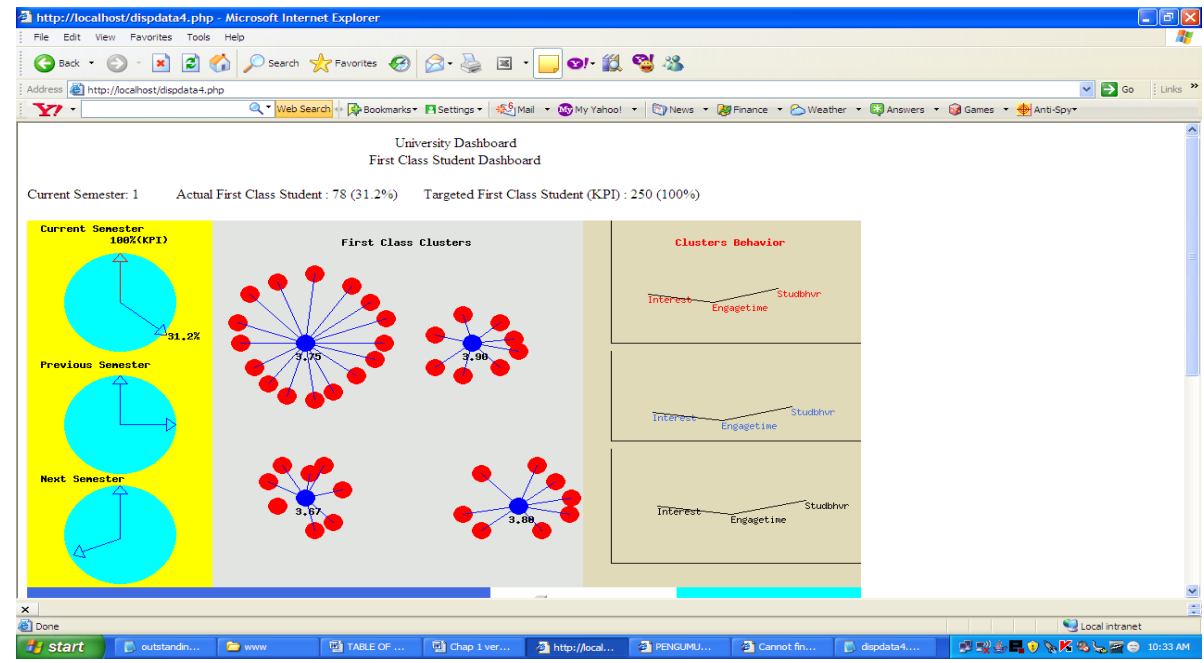

Fig. 3. (a). A Web-based Dashboard System For Higher Education

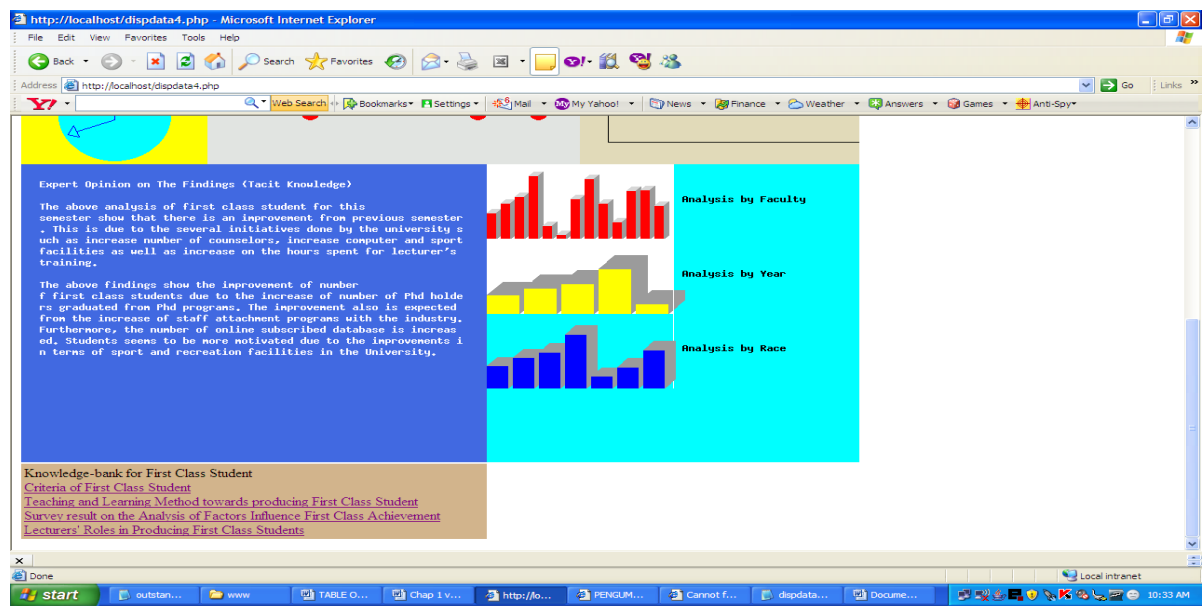

Fig. 3. (b). A Web-based Dashboard System For Higher Education

\subsection{About the Product}

The software products have been developed using Oracle system and open source platform. The backend engines which are K-means clustering and forecasting engines were developed using Oracle forms $6 \mathrm{i}$ and Oracle $10 \mathrm{~g}$ database, whereas the front-end of the digital dashboard was developed using Php programming language and MySQL database which is open source platform. The data required are student's Cumulative Grade Point Average (CGPA), student personal background, lecturer's 
comments and related publications. The system is can be installed in any type of servers which is connected to the internet. The software can be executed by using any browser.

\section{Conclusion}

We propose a holistic design of Knowledge-based Dashboard system which shall improve the understanding of the information through clustering process and enhance the visual impact of the system. By designing the system as a dashboard and embedded with various data retrieval techniques; clustering, visualization and knowledge codification, it shall improve the understanding, visualization and personalization level of the data.

\section{References}

1. Luan, J.: Data Mining and Its Applications in Higher Education. In: Serban, A., Luan, J. (eds.) Knowledge Management: Building a Competitive Advantage for Higher Education. New Directions for Institutional Research, vol. 113. Jossey Bass, San Francisco (2002)

2. Mohd, W.M.W., Embong, A., Zain, J.M.: Parameterless K-Means: Auto-generation of Centroids and Initial Number of Cluster based on Distance of Data Points. In: MalaysianJapan International Symposium on Advanced Technology 2007 (2007)

3. Mohd, W.M.W., Embong, A., Zain, J.M.: Visual and Interactive Data Mining: A Framework for an Interactive Web-based Dashboard System for Higher Education using Graph-based Visualization Technique. In: Malaysian-Japan International Symposium on Advanced Technology 2007 (2007)

4. Mohd, W.M.W., Embong, A., Zain, J.M.: Enhancing Knowledge Codification Through Integration of Tacit-Explicit Knowledge Codification, Transfer Mechanism and Visualization Dashboard: A Holistic Model for Higher Learning Institutions. In: MalaysianJapan International Symposium on Advanced Technology (2007) 